\title{
Behavior of HRES without and with Pitch Angle Control During Frequency Variations
}

\author{
Nihel Khemiri and Adel Khedher
}

\begin{abstract}
This paper proposes the behavior of the hybrid renewable energy system, HRES, without and with pitch angle control during the variation in frequency. The HRES is a wind/PV one. The WG is based on a double fed induction generator (DFIG) when the rotor side converter (RSC) is used to connect the DFIG to DC bus voltage, put with a PV generator. The integration of the HRES in the grid introduces some problems such as the stability of the system and the quality of the injected power. This paper aims is to evaluate the ability of the HRES to remain connected to the grid following some disturbance, such as frequency variations. That is why the HRES will have to participate in primary frequency control. The only method of involving the HRES in the primary frequency control is to reduce the wind power captured by the wind turbine in order to increase the power in the event of a frequency drop.

Simulation results prove that the pitch angle control can keep the HRES connected to the grid during the frequency variations.
\end{abstract}

Index Terms - hybrid renewable energy system HRES; primary frequency control; frequency drops.

\section{INTRODUCTION}

During the last decades, many large HRES have already been installed and have also been integrated in power grids. With the ever-increasing development of wind power, the impacts on the grid become more significant. The effect of wind generation on the system frequency regulation is one of the most problems.

An innovative way for an HRES to participate in some approaches to frequency control using kinetic energy stored in the rotor for a fast power reserve that can be delivered in a short period is presented. This fast kinetic-energy-based reserve is ensured despite wind speed variations. A disoptimization of the power coefficient can modifies the rotor speed set point or the pitch control. In case of a frequency drop, the power coefficient can then be increased to produce more energy. This approach can help to reduce

Published on November 16, 2019

Nihel Khemiri is with the Laboratory of Advanced Technology and Intelligent Systems LATIS, The National School of Engineers of Sousse, University of Sousse. She is an assistant at the High Institute of Applied Sciences and Technology of Kairouan, Avenue Beit El Hekma, 3100, Kairouan, Tunisia.

(e-mail: khemirin@yahoo.fr).

Adel Khedher is with the Laboratory of Advanced Technology and Intelligent Systems LATIS. $\mathrm{He}$ is a professor at the the National Engineering School of Sousse, University of Sousse, 4023, Sousse, Tunisia.

(e-mail: Adel_kheder@yahoo.fr) the dynamics and depth of the frequency drops and therefore allow the HRES to participate in frequency control.

As the mechanical time constant of the DFIG is very higher versus the electrical one the stored kinetic energy of the entire rotor is high and can be used to support the power system [1].

On the other hand, the WG must participate for a long term to ensure primary frequency regulation. This is possible with the addition of a frequency drop in the pitch angle controller and in the electrical active power control loop $[2,3,4]$.

The introduction of a frequency drop controller in the active power control loop returns to run the HRES with a variable loading extracted power [5], hence is increasing the rotational speed. Consequently, the kinetic energy stored in the rotational mass of the WG rises, allowing also a better inertia response capability.

This study focuses on the participation of the HRES in short-term frequency regulation.

This paper is organized as follows: In the second section, the model of the hybrid wind/PV system components is provided. We present in the first and second steps, respectively, the model of the wind turbine and the DFIG. The third one deals with the PV system. The third section presents the wind turbine control for participation frequency regulation. The forth section studies pitch angle control. In the last section, the behavior of the HRES during frequency variations is given and some simulation results are shown. Finally, we finish by some remarks and a conclusion.

\section{Modeling OF Wind Generation System}

The basic configuration of the whole system is presented in figure 1. The studied system is composed of three bladed rotors with a corresponding mechanical gearbox, a DFIG, two power converters (RSC and GSC), DC-bus voltage, a PV generator, a DC-DC boost converter and a grid filter. The coupling of the two subsystems, wind and PV, is made via a DC bus. When the machine is driven above synchronous speed, power is recovered from the rotor, with $\mathrm{RSC}$ working as a rectifier and GSC as an inverter. 


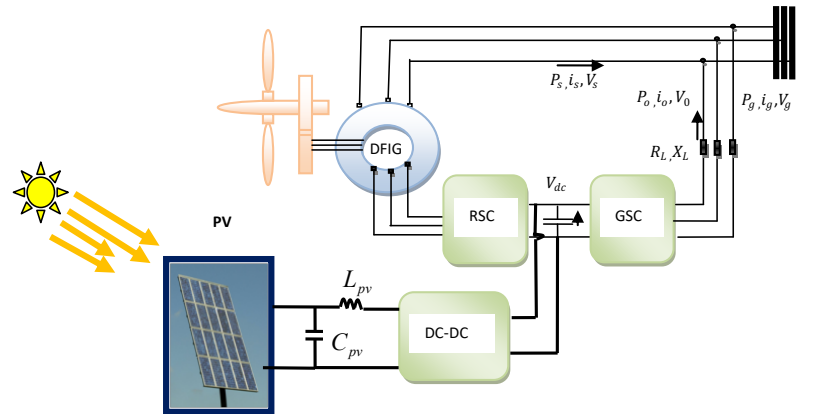

Fig. 1. Schematic diagram of hybrid wind/PV system connected to the grid

\section{A. Modeling of Wind Turbine}

The wind energy is transformed into mechanical energy by a wind turbine. We must include a gearbox that matches the turbine's low speed to the higher speed of the generator. The aerodynamic power, which is converted by a wind turbine, $\mathrm{P}_{t}$, depends on the power coefficient $\mathrm{C}_{\mathrm{p}}$ which is given by [6]:

$$
P_{t}=\frac{\rho \pi R^{2} V_{v}^{3}}{2} C_{p}(\lambda, \beta)
$$

The relation between the wind speed and the aerodynamic torque can be described by the following equation [7]:

$T_{t}=\frac{\rho \pi R^{2} V_{v}^{3}}{2 \Omega_{t}} C_{p}(\lambda, \beta)$

Numerical approximations are developed to calculate $C_{p}$ for given values of $\lambda$ and $\beta$. Here, the following approximation is used [8]:

$C_{p}(\lambda, \beta)=c_{1}\left(c_{2} \mathrm{~g}(\lambda, \beta)-c_{3} \beta-c_{4}\right) e^{-c_{5} g(\lambda, \beta)}+c_{6} \lambda$

Where:

$$
g(\lambda, \beta)=\frac{1}{\lambda+0.08 \beta}-\frac{0.035}{\beta^{3}+1}
$$

and $\quad c_{\mathrm{i}}(i=1,6)$ is given in the Appendix.

The pitch angle, $\beta$, must be controlled to maintain constant electric power. The regulation scheme of the pitch angle is illustrated by figure 2 .

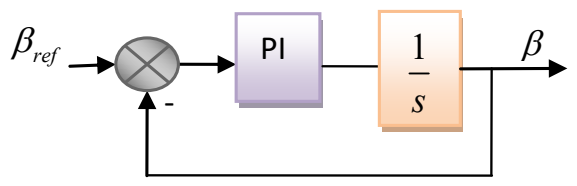

Fig. 2. Regulation of pitch angle by PI regulator

\section{B. DFIG Modeling}

The classical electrical equations of the DFIG in the Park frame are written as follows [9]: $\left\{\begin{array}{l}\frac{d \Phi_{s d}}{d t}=V_{s d}-R_{s} i_{s d}+\Phi_{s q} \omega_{s} \\ \frac{d \Phi_{s q}}{d t}=V_{s q}-R_{s} i_{s q}-\Phi_{s d} \omega_{s} \\ \frac{d \Phi_{r d}}{d t}=V_{r d}-R_{r} i_{r d}+\Phi_{r q} \omega_{r} \\ \frac{d \Phi_{r q}}{d t}=V_{r q}-R_{s} i_{r q}-\Phi_{r d} \omega_{r} \\ \omega_{r}=\omega_{s}-\omega\end{array}\right.$

Where $R_{s}$ and $R_{r}$ are respectively the stator and rotor phase resistances, $\omega=n_{p} \Omega_{m e c}$ is the electrical speed, $n_{p}$ is the pair pole number, and $i_{s d}, i_{s q}, i_{r d}$ and $i_{r q}$ are respectively the direct and quadrature stator and rotor currents. The stator and rotor flux can be expressed as:

$\left\{\begin{array}{l}\Phi_{s d}=L_{s} i_{s d}+M i_{r d} \\ \Phi_{s q}=L_{s} i_{s q}+M i_{r q} \\ \Phi_{r d}=L_{r} i_{r d}+M i_{s d} \\ \Phi_{r q}=L_{r} i_{r q}+M i_{s q}\end{array}\right.$

The stator and rotor active and reactive power is given respectively by equations (6) and (7):

$\left\{\begin{array}{l}P_{s}=\frac{3}{2}\left(V_{s d} i_{s d}+V_{s q} i_{s q}\right) \\ Q_{s}=\frac{3}{2}\left(V_{s q} i_{s d}-V_{s d} i_{s q}\right)\end{array}\right.$
$\left\{\begin{array}{l}P_{r}=\frac{3}{2}\left(V_{r d} i_{r d}+V_{r q} i_{r q}\right) \\ Q_{r}=\frac{3}{2}\left(V_{r q} i_{r d}-V_{r d} i_{r q}\right)\end{array}\right.$

The electromagnetic torque is expressed as:

$T_{e m}=\frac{3}{2} n_{p} \frac{M}{L_{s}}\left(i_{r d} \Phi_{s q}-i_{r q} \Phi_{s d}\right)$

\section{Photovoltaic System Modeling}

The solar cell is the basic unit of a photovoltaic module and it is the element in charge of transforming the sun rays or photons directly into electric power [10]. The solar cell used is the PN union, whose electrical characteristics differ very little from a diode, is represented by the equation of Shockley (9). 


$$
I_{d}=I_{s} \cdot\left[\exp \left(\frac{V_{p v}}{V_{T}}\right)-1\right]
$$

Being the net current of the cell, the difference of the photocurrent $I_{p h}$ and the diode current $I_{d}$ is shown in equation (10):

$I_{\mathrm{pv}}=I_{p h}-I_{\mathrm{d}}$

Considering equations (9 and 10), the PV current is rewritten as follows [11].

$$
I_{\mathrm{pv}}=I_{\mathrm{ph}}-I_{s} \cdot\left[\exp \left(\frac{V_{\mathrm{pv}}}{V_{T}}\right)-1\right]
$$

After neglecting $R_{s}$ and $R_{s h}$ effects, the ideal model of $\mathrm{PV}$ cell is given by figure 3 .

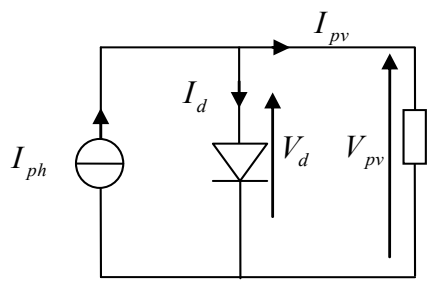

Fig. 3. Simplified electric model of photovoltaic cell

\section{Wind TURBINE CONTROL FOR PARTICIPATION IN FREQUENCY REGULATION}

The participation of the wind turbines in the frequency regulation requires having a reserve of power. The easiest way for wind turbines to dispose of this reserve is to operate below the capabilities offered by wind speed. Because of the fatal nature and scarcity of this source of energy, there is a shortfall. After the presentation of technical connection conditions requesting to participate in the primary frequency regulation of wind farms, we will study the solution offered by the wind turbine technology considered to participate in this regulation.

The only way to involve the wind turbines in the frequency setting is to reduce the power captured by the turbine in order to increase the power in the event of a drop in frequency [12].

Operating with the power reserve " $\Delta P_{T}$ " implies that the power extracted by turbine $P_{T}$ is lower than the available power $P_{T-\text { avaible }}$ in a normal operation, which is given by:

$\Delta P_{T}=P_{T-\text { avaible }}-P_{T 0}$
To create this reserve, we reduce the power extracted by the turbine by controlling the blade pitch angle. This most trivial solution is the most common and can be used throughout the wind turbine's operating area $[13,14]$. The operation of a wind turbine with a power reserve is illustrated in figure 4.

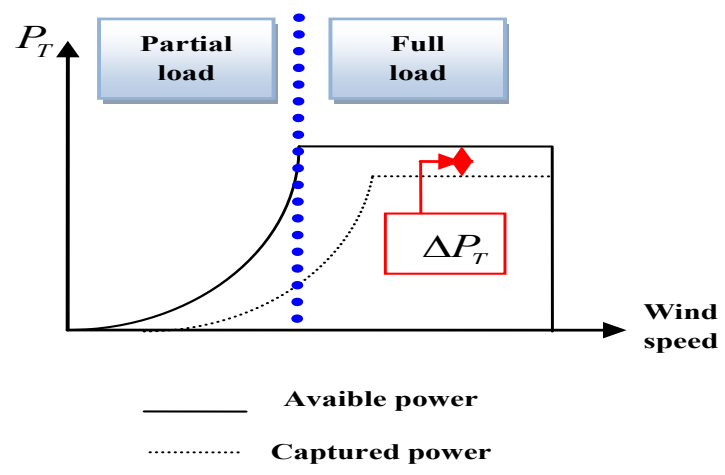

Fig. 4. Operation of wind turbine with power reserve

\section{Pitch Angle Control}

In a normal operation, the control of the angle pitch " $\beta$ " makes it possible to limit the power captured by the turbine to its nominal value[15]. The increase in the pitch angle decreases the lift of the blade, which reduces the torque of the turbine, and so does the extracted power. This is what we see on characteristics $C p(\lambda, \beta)$ : When $\beta$ goes up, $C p$ goes down. Whatever the wind speed, it is therefore possible to act on the angle to raise or decline the power extracted by the turbine [16]. To achieve the management of the power injected into the grid of the DFIG for their participation in the frequency regulation, a droop is introduced in the power control of the wind turbine [17]. For the implementation of the frequency control are required the following conditions:

- Droop $\delta=5 \%$

- Power reserve $\Delta P_{T}=13 \%$

- Operation at full load

The implementation of the frequency control is expressed as:

$P_{\text {Tref }}-P_{T}=\left(\left(f_{0}-f\right) \frac{P_{T-\text { avaible }}}{\delta}+P_{T 0}\right)-P_{T}$

$\beta_{\text {ref }}=C(s)\left(P_{\text {Tref }}-P_{T}\right)$

Where $\mathrm{C}(\mathrm{s})$ is a power regulator, which is a proportional integral type. 


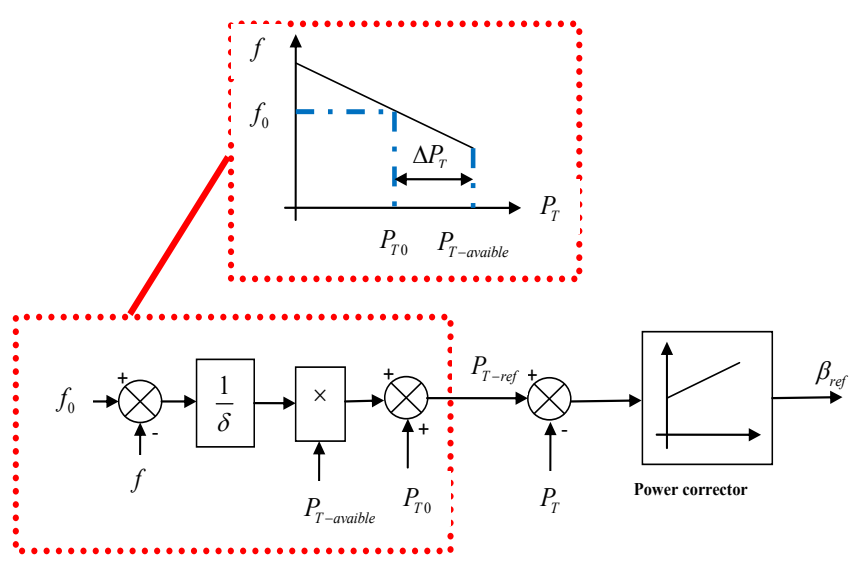

Fig. 5. Implementation of frequency control

\section{Simulation Results}

The analysis is carried out in a MATLAB/SIMULINK environment. Simulation results are made by using the real parameters of the HRES as follows:

- Wind turbine AE46 and DFIG rated at $660 \mathrm{KW}$ and $690 \mathrm{~V}$

- Photovoltaic power systems at 96KW and 690V

- Profile of considered frequency variations

The system of parameters is given in the Appendix. The profile of studied frequency variations depicted in figure 6 .

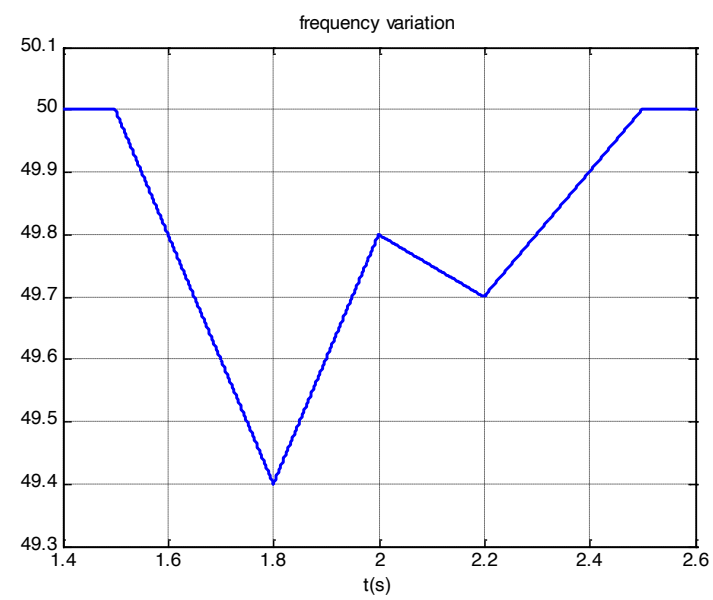

Fig. 6. Profile of studied frequency variations

We are interested here in studying the behavior of the HRES during frequency variations. The objective is to evaluate its ability to stay connected to the grid following such variations.

Figure 7 shows the participation of the HRES in the primary frequency regulation by the pitch angle control.

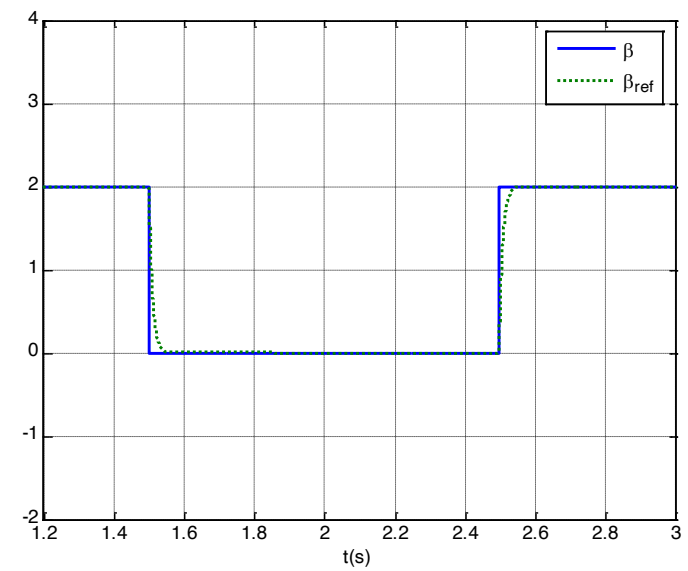

Fig.7. Participation of HRES in primary frequency regulation by pitch angle control

Figure 8 illustrates the mechanical speed and the PV, stator-active and grid power with and without pitch angle control during the frequency variations.
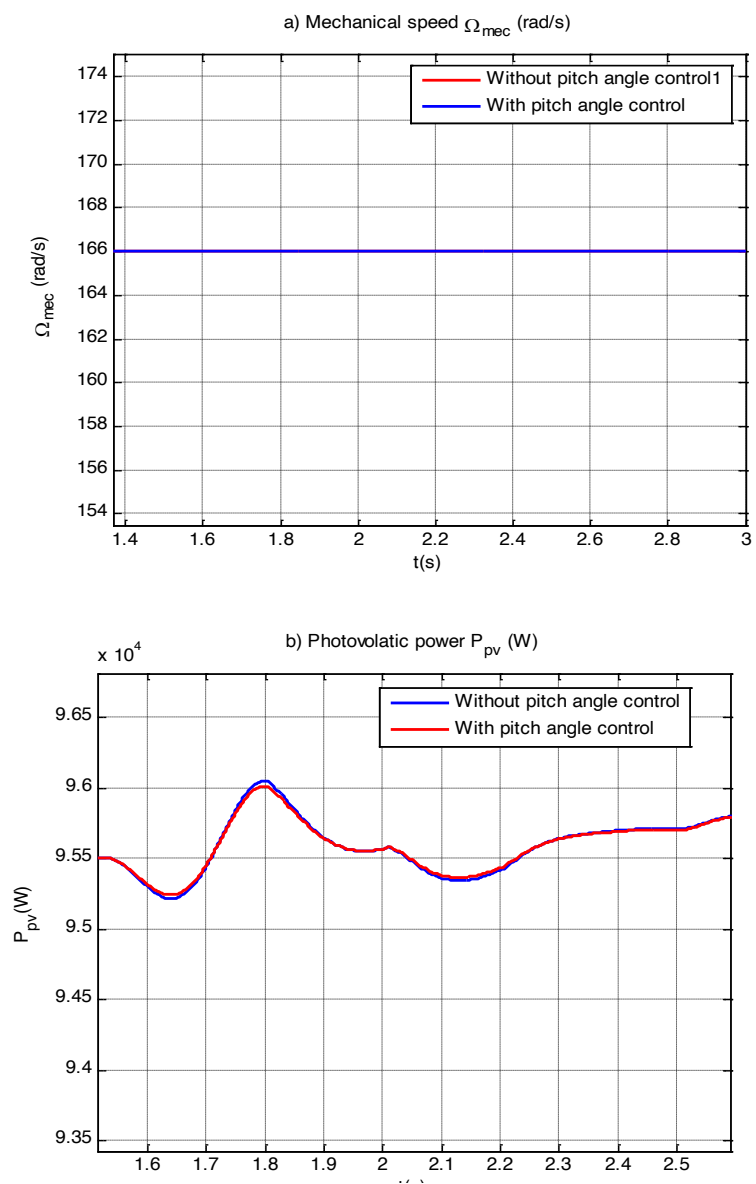

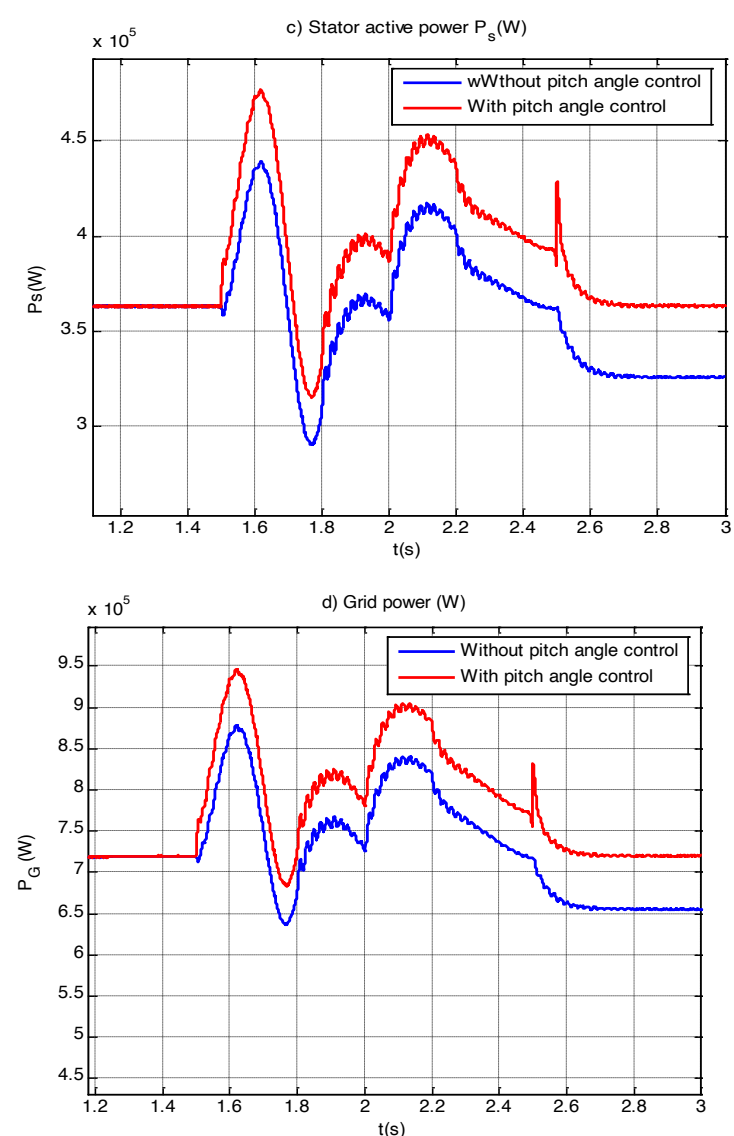

Fig. 8. HRES behavior with and without pitch angle control during frequency variations: a) mechanical speed $(\mathrm{rad} / \mathrm{s}), \mathrm{b}) \mathrm{PV}$ power $(\mathrm{W}), \mathrm{c})$ stator active power (W), d) grid Power (W)

We note that the mechanical speed of the DFIG is controlled via the rotor side converter. In a normal operation, this speed is adapted according to the wind speed in order to optimize the energy conversion. A variation in frequency will therefore have little influence on this structure since the speed variation in the stator rotating field will be compensated by that of the rotating rotor field in order to maintain the angular velocity at its reference value. Photovoltaic power is less sensitive to frequency variations. However, the stator and grid power is more affected by the frequency variation.

We conclude that the stator and grid power is not restored at $\mathrm{t}=2.5 \mathrm{~s}$ when returning the frequency to its nominal value. Pitch angle control proves good control of the active power.

The HRES responds correctly to the primary frequency setting by rapidly increasing its power according to the frequency variation thanks to the implementation of the droop.

The HRES responds very quickly to the set point variation. The power reserve is restored with the return of the frequency to its nominal value at $t=2.5 \mathrm{~s}$ by the action of the primary regulation by controlling the pitch angle. The
RSC automatically adjusts the operating point of the machine to the supply conditions.

\section{CONCLUSION}

In this paper, an interconnected grid hybrid renewable energy system, HRES, has been described and modeled. The first subsystem consists of a wind energy conversion system, WCES, based on the DFIG, and the second consists PV generator operate in the MPPT area.

The study of the frequency variation has shown that the stator-active power and the grid power are affected by this variation. In this context, the HRES must participate in the primary frequency regulation. The principle of this regulation is to reduce the power captured by the wind turbine in order to increase the power in the event of a drop in frequency. This is called "operation with power reserve". To create this reserve, the power extracted by the turbine has been reduced by controlling the pitch angle of the blades by introducing a droop into the control of the power extraction. Pitch angle control prove good control of active power. The HRES responds very quickly to the set point variation, and the power reserve is reconstituted with the return of the frequency to its nominal value.

\section{APPENDIX}

Wind turbine data: $\mathrm{P}_{\mathrm{n}}=660 \mathrm{~kW}, \mathrm{R}=21.165 \mathrm{~m}, \mathrm{C}_{\mathrm{pmax}}=$ $0.42, \lambda_{\text {opt }}=9, \mathrm{G}=39, \mathrm{~J}=28 \mathrm{Kg} \mathrm{m}^{2}, \mathrm{f}=0.01 . \mathrm{o}$

$\mathrm{r}$

Power coefficient constants: $\mathrm{c}_{1}=5109, \mathrm{c}_{2}=116, \mathrm{c}_{3}=0.4, \mathrm{c}_{4}$ $=5, \mathrm{c}_{5}=21, \mathrm{c}_{6}=0.0068$.

Induction generator data: Rated power: $660 \mathrm{KW}$, Rated stator voltage: $400 / 690 \mathrm{~V}, \mathrm{f}=50 \mathrm{~Hz}, \mathrm{R}_{\mathrm{s}}=0.0146 \Omega, \mathrm{R}_{\mathrm{r}}=$ $0.0238 \Omega, \mathrm{L}_{\mathrm{s}}=0.0306 \mathrm{H}, \mathrm{L}_{\mathrm{r}}=0.0303 \mathrm{H}, \mathrm{M}=0.0299 \mathrm{H}$, Number of pair poles: $n_{p}=2$.

PV System : $N_{p}=44, N_{s}=59, I_{c c}=159 \mathrm{~A}, V_{c o}=773 \mathrm{~V}, C_{p v}=$ $0.01 \mathrm{~F}, L_{p v}=0.03 \mathrm{H}, C=68 \mu \mathrm{F}, \mathrm{R}=30 \Omega, K=1.38 \mathrm{e}-23 \mathrm{~J} / \mathrm{K}$, $q=1.6 \mathrm{e}-19 \mathrm{C}$.

\section{REFERENCES}

[1] O. Anaya Lara,.M. Hugues f, N. Jenkins, G. Strbac, "Contribution of DFIG-based wind farms to power system short- term frequency regulation", IET Proc.-Gener. Transm. Distrib., 2006, 153, (2), pp. 164-170.

[2] G. Ramtharan,.B. Ekanayake , N. Jenkins,"Frequency support from doubly fed induction generator wind turbines", IET Renew. Power Gener., 2007, 1, (1), pp. 3-9.

[3] H. Chowdhury ,T. Mah,'Frequency regulation with wind power plants". Power and Energy Society General meeting - Conversion and Delivery of Electrical Energy in the $21^{\text {st }}$ century, IEEE, July 2008, pp. 1-5.

[4] G. D almeida ,, J. Es lopes,"Participation of doubly fed induction wind generators in system frequency regulation", IEEE Trans. Power Syst., 2007, 22, (3), pp. 944-950.

[5] N. Khemiri, A. Khedher, MF. Mimouni,",A Crowbar Protection Technique for Hybrid Renewable Energy System During Voltage Dips". 13th International conference on Sciences and Techniques of 
Automatic control \& computer engineering, December 17-19, 2012, Monastir, Tunisia.

[6] N. Khemiri, A. Khedher, MF. Mimouni,"Wind Energy Conversion System using DFIG Controlled by Backstepping and Sliding Mode Strategies", International Journal of Renewable Energy Research, Vol.2, No.3, 2012

[7] N. Khemiri N, A. Khedher, MF. Mimouni,"Steady-state performances analysis of wind turbine using DFIG drive connected to grid" International Conference on Electrical Systems and Automatic control. JTEA 26-27-28 Mars 2010.

[8] Khemiri,A. Khedher, M.F Mimouni,"An Adaptive Nonlinear Backstepping Control of DFIG Driven by Wind Turbine", WSEAS Transactions on Environment and Development, Issue 2, Vol. 8, April 2012.

[9] E. Mahersi, A. Khedher, M.F Mimouni, "The Wind energy Conversion System Using PMSG Controlled by Vector Control and SMC Strategies", International Journal of Renewable Energy Research, Vol.3, No.1, 2013.

[10] A. Al Nabulsi," Efficiency Optimization of a DSP-Based Standalone PV System Using Fuzzy Logic and Dual-MPPT Control ", Industrial Informatics, IEEE Transactions on. Vol. 8, Issue 3, Aug. 2012, pp. $573-584$.

[11] R.Stala," Individual MPPT of photovoltaic arrays with use of singlephase three-level diode-clamped inverter industrial Electronics (ISIE)", IEEE International Symposium on, pp.3456 - 3462, 4-7 July 2010 .

[12] N. Laverdure, ,"Sur l'intégration des générateurs éoliens dans les réseaux faibles ou insulaires", Thèse de Doctorat en Génie Électrique de l'Institut National Polytechnique de Grenoble, Décembre 2005

[13] J. Ekanayake, N. Jenkins, "Comparison of the Respons of Doubly Fed and Fixed- Speed Induction Generator to Changes in Network Frequency", IEEE Transaction on Energy Convertion, Vol.19, Issue 4, December 2004

[14] S. Emelin, "Étude de stratégies de réglage coordonné des éoliennes d'une ferme pour la participation au réglage primaire de fréquence", Master 2 Recherche de Génie Electrique de Grenoble Institut National Polytechnique, 2009

[15] R. Ullah, T. Thiringer, D. Karlsson, "Temporary Primary Frequecy Control Support by Variable Speed Wind Turbines - Potential and Applications", IEEE Transaction on Power Systems, Vol.23, Issue 2, May 2008.

[16] E. Obaid ,L.Cipicigan, L.Abrahim, M. Muhssin.” Frequency contro of future power systems: reviewing and evaluating challenges and new control methods”, Journal of Modern Power Systems and Clean Energy, pp 9-25, Vol. 7, Issue 1, January 2019.

[17] M, . ateem, M. asad bashir," Detecting and monitoring of voltage and frequency variation and under ground cable fault location using check point method", 2018 international conference on computing mathematics and engineering technologies (icomet), 26 April 2018, Pakistan.

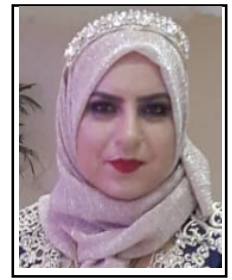

Nihel Khemiri was born in Mahdia, Tunisia in 1981. He received the Electrical Engineering and Master degrees from the Tunis Engineering School (TES), in 2005 and 2006, respectively, the Ph.D. and the academic accreditation degree in Electrical Engineering from the Monastir Engineering School (MES) in 2013. In 2013, she has been an assistant professor in the Electronoic Department of High Institute of Applied Sciences and Technology 